\section{INTERVIEW WITH JOE LUPO}

INTERVIEW BY ROGER GROS

Roger Gros is the publisher of Global Gaming Business and is based in Las Vegas, Nevada, and Atlantic City, New Jersey.

J oe Lupo was a critical part of the Borgata from the time it opened in 2003 to the time MGM Resorts (it has been half-owner with Boyd Gaming) bought the full interest in the property in 2017. He joined Hard Rock International in January 2017 when he was named president of the company's Tampa property. In October 2018, he was appointed president and CEO of Hard Rock Atlantic City, where he has been responsible for elevating the visibility of the Hard Rock brand and boosting casino revenues substantially.

ROGER GROS: You have had a tough time in Atlantic City over the last few months, which opened up about three weeks ago. Why don't you fill us in on how it has been going since then?

JOE LUPO: Well, we have been making the best of the hand that we had dealt to us. People are pleased with what we have been able to provide. It was important for us to be transparent, specifically about what we could not provide. I think that has been really helpful, to set that expectation.

Here at Hard Rock, we have some great outdoor balconies that look over the ocean, and we have set up some great dining for our customers to sit outside. We have tried to do the best job that we can.

We have got probably as much Plexiglas around the property as anyone, if not more. I think that was a help. We were quick to jump on that. It has been important that we really impress this - our safe and sound protocols with the help of our Hard Rock division down south.

I have hired quite a bit of people, knowing that we have 1,200 fewer employees than what we did when we shut down. But we actually have more cleaning crew, and they are very evident, very available for you to see.

It has been really important that we set that tone, that we are safe, we do have a clean property, we are enforcing the wearing of masks. As far as playing, you can play safely and have a nice experience out here at the Jersey Shore.

ROGER GROS: Joe, I have heard some good comments from people and on Facebook about the experience at Hard Rock. It is not easy to operate during these times, but that is always nice to hear.

JOE LUPO: I could not be more pleased. We probably have over 15,000 surveys that we are asking all of our customers to complete, and we are asking for feedback. We want to ensure that they feel comfortable. We have gotten not only a great response, but an overwhelmingly positive response, better than what I thought we would receive.

We set that right expectation, we ensure that we maintain our rules and policies, and we have gotten a great response. We have been compared to other properties, and I am really happy that people feel that we have one of the safest properties in Atlantic City.

ROGER GROS: No question about that. So let us go back to the beginning of the shutdown. How much guidance did you get from the regulators when the shutdown order was given?

JOE LUPO: That was a tough issue for everybody. We heard a lot of things from the regulators and the governor. Obviously, we were working closely with everyone. We started having meetings the week before, and I got the management staff around the table to anticipate what might happen.

When we did get that notification-I think it was on a Monday morning - we literally were shut down by 2:00 p.m. that day. I did not really want to get the ball rolling that day and then have to tell people they could not come in.

It was a tough issue for everybody, but we had good guidance, and we have been working well with the 
New Jersey Division of Gaming Enforcement, and the Governor's Office has been communicative, as well.

ROGER GROS: What was your strategy to stay in touch with your customers throughout the lockdown?

JOE LUPO: That was really important. We kept on some of our player development staff, and we were in touch with a lot of our customers. Obviously, it was not about promoting the business. It was just making sure that they were okay and asking if they needed anything. You develop some strong relationships in a high-frequency market like Atlantic City, where many customers know how many kids I have, their names, and saw them being raised over the years. You really develop friendships.

We did a lot of cold calling with our customers, seeing how they were doing. We spent a lot of time and effort on videos and e-mails. We tried to be as communicative as possible and, again, be transparent about what we knew, what our expectations were, and the changes that people would expect when the doors would open again.

ROGER GROS: Sure. Hard Rock has one of the best online casinos in the state, certainly, with the people running it there. They are the top of the line. Did you direct people to that if they still wanted to stay active in gambling?

JOE LUPO: We did if they were interested. We were not pushing it too much. Obviously, a lot of people were out of work and going through some tough times. Here in New Jersey, when it started out, New Jersey's numbers were through the roof, along with New York.

We wanted to be sensitive to the issues that people were going through. The online team did increase their spending on advertising, on TV and some other advertising mechanisms. But I did not think it was the time to push too hard.

It was more about how people were doing, concern over friends and family that we have known for years here in Atlantic City.

ROGER GROS: Absolutely. Another group you wanted to stay closely in touch with was your employees. How did you stay engaged with them throughout this period?
JOE LUPO: They are the backbone, you know? We heard from them a lot. I kept on a few HR, or human resources, individuals. We really went over and above to try and communicate with them with both through e-mail and direct mail, and we set up some phone systems so they would have direct access to ask us questions. We wanted to hear their feedback and see how they were doing.

We heard a lot of feedback, and we could not be more thankful to our owners showing their support. They wanted to make sure our employees had food on their tables. We gave away over a million dollars in ShopRite gift cards over a few different periods.

And they would come in. Everyone wore masks, and they drove through the porte-cochère, and we would hand those out. I am telling you, it was dramatic. People were just in tears and thankful and could not have been more happy.

It also gave us a chance to see our employees. When you work $24 / 7$, seven days a week with people, you build those relationships. They were able to come in, ask questions, and it was really important to stay communicative with them.

ROGER GROS: I think you did a great job there. There seemed to be a lot of loyalty because of that.

JOE LUPO: $100 \%$. I know we are getting a very good response from the individuals when we did reopen. They were really hungry to come back to work and thankful to come back to work, and it has probably been one of the most gratifying parts of my job once I did return and see the employees back, just continued thanks - you know, thank-yous for what we did for them.

Again, it really goes back to Jim Allen and the tribe paying benefits through July and paying two weeks when we first closed, then getting another couple weeks of additional vacation time that they could use. I just cannot say enough about the company.

ROGER GROS: No question. So there was a lot of fits and starts about when you were going to reopen. But finally, in early July, you got the word. How did you prepare for that?

JOE LUPO: Well, we were pretty prepared from the get-go. We really did not think we would be closed that long. 
From the moment we closed, we started cleaning the property. Not knowing as much as we do today about COVID, about transferring the virus through touching surfaces, we disinfected and sanitized this building like you cannot believe, and within a month, we had the entire building clean. So we were pretty prepared to open.

We got late notice about the some of the requirements for Plexiglas. We had to really scramble for that, but we were pretty aggressive on that from the get-go. I probably had more games open on the day that we were able to than many other properties.

We just took a very aggressive approach towards trying to be ready. Cleanliness was not an issue. Our rooms were clean. The real scramble was for outdoor dining. I believe we did not get that notice until Monday, and we opened on Thursday. At that time, we believed we were going to have $25 \%$ indoor dining.

That was a little bit of a scramble to come up with. We currently have three outdoor balconies that we can serve food on. Our food and beverage team had our toughest challenge, but they came through and worked hard. There was 24 hours of work the last three days to be able to get the dining available for our customers.

Then it was more about hotel rooms. How many should we book? How many can we feed? What is the experience going to be like? What about the promotions? People cannot stand on line. They cannot congregate. So what kind of promotions can we do?

We did not have a lot of notice. We probably had just over a week, but we were able to get the job done. I really could not be more proud of the team for doing so.

ROGER GROS: You had an opportunity to be very creative with this outdoor dining. As you say, you have all these great decks out there, so you had an advantage some of the other casinos did not have. How did you figure out how to configure that, and how did your team get creative?

JOE LUPO: It really evolved. The first week was a scramble, and we opened two of the decks. We have a new deck that we never used before. It was the old Scores deck, and it overlooks the pier and the ocean. It is beautiful. There was a bar out there. So, again, the facilities team, the food and beverage team, and the EDS team really did a great job of getting it clean, getting it ready.

I made some phone calls to some people we had developed long-lasting relationships with and said, "I need your help. Why do you not just come out here today? I need some banners, and I need shade, and I need some flyers and things like that." Over the course of time you build those relationships, and they were very helpful.

The first week we realized we did not have enough seating for our top-tier guests, our Rock Royalties and X Card. The second week we changed things around and made one of the decks available just for them, because they primarily come on weekends.

The third weekend, we added another deck that was not ready in time. We added more tents and rented more tents, and we came up with a way to execute dining on that third balcony. Now that is available for our highest-tier card, our X Cards only.

So we have developed, and we have to be flexible, and we have never been in this position. You have got to be ready for the changes. The team has done a great job. We have tweaked menus and pricing. We gave some more comp dollars to our higherend tier.

Now we are serving a full menu out of the Council Oak kitchen on one deck. We have a great fine dining availability on another deck. And we have more of a mass execution out of our buffet that sits on the second floor.

We have been able to use those kitchens, and we have done a great job by being flexible. We keep looking at it and looking at it and seeing how we can change to be more efficient, more productive, and provide a better experience to the guest.

ROGER GROS: The casino environment is totally unlike it was previous to the shutdown. How have your customers responded to all the stipulations with the masks, the Plexiglas, and all those kinds of things?

JOE LUPO: You know what? It has been better than I expected. We have gotten pretty good response. Saturday night was really busy in here, and we have not had any issues with masks. I have not 
had any issues with Plexiglas. Individuals cannot smoke, so every time they want to smoke, they have to go outside. They cannot have a drink other than a bottle of water. Obviously, if they could, they would probably play longer. But they understand the situation.

And it is consistent. There is no competitive advantage at any of the nine properties other than what the property layout is. From a gaming standpoint, we feel pretty good. The $25 \%$ occupancy really has not hurt us a whole lot. We are obviously down in some volume of players, those that are older are more tentative to come in. Everything has worked out pretty well, and I really cannot complain about the fact that the people have been upset, or there have been issues. They have been very understanding.

ROGER GROS: Yeah, absolutely. Your employees are obviously a big part of that. They have to wear the masks, as well. Have you been able to mitigate their concerns about the virus and things of that nature?

JOE LUPO: It was really important to communicate with them, and they went through extensive training before we opened. The Plexiglas was a big help to the dealers. I went down to Tampa when they first opened, and I spoke with the dealers down there. They felt so much safer with the Plexiglas in front of them.

So when I came back here, we started moving forward with the Plexiglas, and I think it got us a little bit ahead of others, going down to a corporate support that was open, the Tampa property, before Atlantic City was.

The employees have to feel safe, right? They are going to communicate with the customers, and they are our backbone. So it is really important that they felt good.

We have set up a committee they can meet with once a week. The committee is made up of department trainers. They were trained by AtlantiCare. All the employees have an option to either go to the meeting, get messages to those trainers, let us know if they feel uncomfortable or if they feel very comfortable, and give feedback from the customers about resources, about training, about policies, whatever the case may be.
We wanted to really ensure we had a good communication mechanism between the employees and management so we could make those changes.

ROGER GROS: Sure, absolutely. New Jersey seems to be one of the few states now where the epidemic has subsided a bit. How long do you expect to operate under the current stipulations before they start to be relaxed?

JOE LUPO: I think that is the million-dollar question. I really do not know. That is up to the governor. We are hoping that he opens things up here sooner than later.

It is not just about the casinos, it is about the whole restaurant and tourism industry here in New Jersey, the whole Jersey Shore. One thing I do know is that the casinos have better air filtration systems than most of the restaurants and hospitals. We have big restaurants where we can space people out.

I think the casinos are set up much more beneficially than smaller restaurants. But that being said, the small restaurant owner needs to get open, too, at some point.

I am hoping that we hear something soon, and I know we will be able to do it well. We have shown that. I watch the governor's report every day to hopefully hear something positive.

ROGER GROS: In an interview with Global Gaming Business, your Hard Rock Corporate Entertainment Director gave us some really good advice on how you are going to move forward.

But how are you looking in Atlantic City? You have got some great facilities there, with the Etess Arena and the smaller theater, as well. How is entertainment going to return to the Hard Rock?

JOE LUPO: I do not think we are going to have entertainment in the same fashion of concerts real soon. I am probably looking at 2021.

We are seeing a lot of stuff from September and October get pushed out. We closed in March, so we had concerts planned for the summer that, at that time, I was expecting or hoping that we would have them. A lot of the stuff has been moved an entire year. We had Rod Stewart in August, and he booked for August 2021. 
A lot of the concerts are just booking a full year in advance.

I do not think we are going to have a whole lot during the end of the year. There might be a chance. The one thing I am excited about, if we do have an occupancy limit, like $25 \%$ or $50 \%$ here at Hard Rock Atlantic City, we have the biggest venue of any property. We can seat over 5,000 people.

I can get 1,200 people in that venue for a concert, and entertain a pretty good amount. I am looking forward to that. Entertainment is a big piece of our business. I am hoping that we have some lounge acts sometime in the fall, just to create some energy. That is important to us. And we are talking about doing something on a roof for a small group of people. We are not letting this tie us down, and as things open up, we just have to be creative and flexible.

ROGER GROS: You mentioned going down to Tampa and seeing how they opened there. You know, even before that, Hard Rock had instituted a company-wide COVID-19 response. I was speaking with Mark Birtha out in Sacramento about how he used some of the corporate guidelines to open up. How did that help you reopen in New Jersey?

JOE LUPO: It was great. Any time you can have corporate support, it is so beneficial, and especially in high-volume properties. Mark does a great job in Sacramento, and our new property in Cincinnati opened about a week or two before us.

From my standpoint, I was able to communicate with Mark and others in terms of what they are seeing and what they are doing. Like I said, I went down to Tampa.

The corporate team did a great job. A lot of individuals, from all of our properties, were involved in helping to develop a plan. And then obviously, we had to tweak ours a little bit due to the fact that New Jersey regulators oversee our casino as opposed to being in other jurisdictions.

And then the CANJ [Casino Association of New Jersey] has been really helpful. Steve Callender has done a great job overseeing that, and we have probably grown to have a better relationship with each other over this time than in my 14 years here.
Ron Baumann came to town at Caesars, and Tom Pohlman over at the Nugget. Mark was over at Resorts. It created a situation where we talked a lot more, communicated a lot more, and got AtlantiCare involved. It has really created a nice bond. We all realize we need to work together to get the city moving forward. That has been really helpful, also.

ROGER GROS: They passed a couple of bills in the state legislature about tax relief. Is that going to be enough to tide you over before you are back to full strength?

JOE LUPO: I hope so. I just do not know how long this is going to last.

ROGER GROS: Nobody does.

JOE LUPO: We are going to be okay. We have one of the strongest balance sheets of any casino organization in the country, Seminole Gaming. So I am not concerned about that.

Jim Allen and our partners, the Jingolis and Jack Morris, they are very supportive of the employees, as you can tell by what they did for them. I have got no issues there.

It is just a matter of when we see the bulk of the volume bounce back and what schooling is going to be put in place. That might have an effect on trips and visitation.

What if there is a vaccine? There are a lot of question marks. In the meantime, we are pretty happy with the volume. We need to ensure that a safe and sound environment that we have here in Atlantic City, Hard Rock Atlantic City. We need to maintain that and build confidence and trust in our customer base.

ROGER GROS: Sure. Meetings and conventions have always been a big part of the AC business. When do you think that is going to be ready to come back?

JOE LUPO: We are seeing a lot booked in 2021. We have a pretty strong 2021 schedule, and it is a big piece of our business.

We have 150,000 square feet of convention space. Our team has been very active. We have brought back about half of that team. We had a lot of action booked over the fall, and so a lot of that is moving. 
We are moving that, and we are providing different protocols for when conventions do come back.

Again, Hard Rock has so much space, and the casinos having more space than your typical city hotel, where you might have a convention, provides us an opportunity.

It is a matter of being aggressive, while maintaining the protocols and the safety of everybody. I think we can do that. I feel very comfortable we can do that. But it probably will not come around until 2021.

ROGER GROS: You are right, you have all that space. The ballrooms are huge. The hallways are huge outside of the ballroom. So I think you have the perfect situation, where you can social distance and keep everybody feeling comfortable.

JOE LUPO: Yeah, we are looking forward to the convention business coming back, that is for sure.

ROGER GROS: So how confident are you that the Atlantic City casinos will be able to return to profitability when this thing is over, whenever that might be?

JOE LUPO: I am very comfortable with that. We have seen pretty good numbers so far. We are seeing volume down, but the people that are coming are playing a little bit longer. It's about building that trust and confidence.

The one thing you have seen here in New Jersey is that we have gone through the worst, according to the numbers, of COVID and amount of transmissions.

The protocols that the governor put in place enforcing wearing masks months and months ago have been really helpful. People have seen that.

The New Jersians, the locals, New Yorkers, and even people outside Pennsylvania, have been living with this a little bit differently than in Florida and California. They are pretty comfortable.

I do not know how the schools will affect visitation, whether there will be another ramp-up, whether there will be a vaccine. But I am pretty comfortable that things will continue to improve over time. I do not know whether nine casinos will be the right number, or whether that will go down to eight or seven.

I need a little bit more time. We have only been open a month. I am not sure.

It has been a wacky period of time, so my time is moving on me. We just need more time to get out of the summer to see really what the fall is like. 